\title{
ARTICLE Combination of iTRAQ proteomics and RNA-seq transcriptomics reveals multiple levels of regulation in phytoplasma-infected Ziziphus jujuba Mill
}

\author{
Xia Ye ${ }^{1,2}$, Huiyu Wang ${ }^{1,2}$, Peng Chen ${ }^{1}$, Bing Fu ${ }^{1}$, Mengyang Zhang ${ }^{1}$, Jidong $\mathrm{Li}^{1}$, Xianbo Zheng ${ }^{1}$, Bin Tan ${ }^{1}$ and Jiancan Feng ${ }^{1}$
}

\begin{abstract}
Jujube witches' broom (JWB) is caused by infection with a phytoplasma. A multi-omics approach was taken during graft infection of jujube by JWB-infected scion through the analysis of the plant transcriptome, proteome and phytohormone levels. A high number of differentially expressed genes (DEGs) were identified 37 weeks after grafting (WAG), followed by observation of typical symptoms of JWB at 48 WAG. At 37 WAG, the majority of the upregulated DEGs and differentially expressed proteins (DEPs) were related to flavonoid biosynthesis, phenylalanine metabolism and phenylpropanoid biosynthesis. Two of the four upregulated proteins were similar to jasmonate-induced protein-like. Among the downregulated genes, the two most populated GO terms were plant-pathogen interaction and plant hormone signal transduction (mainly for tryptophan metabolism). Moreover, phytoplasma infection resulted in reduced auxin content and increased jasmonate content, indicating that auxin and jasmonic acid have important roles in regulating jujube responses during the first and second stages of phytoplasma infection. At 48 WAG, the two largest groups of upregulated genes were involved in phenylpropanoid biosynthesis and flavonoid biosynthesis. Both genes and proteins involved in carbon metabolism and carbon fixation in photosynthetic organisms were downregulated, indicating that photosynthesis was affected by the third stage of phytoplasma infection.
\end{abstract}

Horticulture Research (2017) 4, 17080; doi:10.1038/hortres.2017.80; Published online 27 December 2017

\section{INTRODUCTION}

Jujube (Ziziphus jujuba Mill.) is a major fruit crop cultivated in India, Russia, the Middle East, southern Europe and, especially, China. ${ }^{1}$ Among the diseases of jujube trees, jujube witches' broom (JWB) is currently the most destructive and devastating disease in Asia. ${ }^{2,3}$ JWB is caused by a phytoplasma that can be transmitted by insect vectors and grafting. The typical symptoms of a phytoplasmainfected jujube include excessive stem production from a single point (witches' broom), yellowing and floral organs turning into leaf-like structures (phyllody). ${ }^{2}$

Phytoplasmas are important agricultural pathogens ${ }^{4}$ and have been found in over 1000 plant species worldwide. ${ }^{5}$ Recently, phytoplasma effector proteins have been shown to target transcription factors, phytohormone receptors and other components of phytohormone signaling in the host plant in order to modulate plant development. ${ }^{6-11}$ For example, overexpression of the phytoplasma effector SAP54 induces indeterminate leaf-like flower development in Arabidopsis plants. ${ }^{6}$ The effector SAP11 from Aster Yellows Witches' Broom (AY-WB) Phytoplasma alters Arabidopsis morphology, destabilizes Arabidopsis CINCINNATA (CIN)-related TEOSINTE BRANCHED1, CYCLOIDEA and the PROLIFERATING CELL FACTORS 1 and 2 (TCP) transcription factors, and reduces lipoxygenase (LOX2) gene expression and jasmonate (JA) synthesis. ${ }^{7}$ The TENGU effector causes Arabidopsis sterility by downregulating the JA and auxin pathways. ${ }^{10}$ Together, these results indicate that phytoplasma effectors have vital roles in phytoplasma pathogenesis and host-pathogen interaction. However, phytoplasma effectors have not been identified in woody plants, and it was unknown whether the phytoplasmas that infect trees carry effectors and whether these effectors have similar functions as those in Arabidopsis.

The plant response to phytoplasma infection has also been studied at the physiological and biochemical levels. These studies have shown that phytoplasma infection affects photosynthetic activity, $^{12}$ increases antioxidant enzyme levels and reduces the contents of chlorophyll, total soluble sugars and auxin in infected plants. ${ }^{13,14}$ An imbalance in phytohormones has been suggested to be a main reason for development of phytoplasma-associated symptoms, such as stunting, proliferation and witches' broom. ${ }^{14}$ Previous studies indicated that biosynthetic pathways for such secondary metabolites as terpenoid indole alkaloids and phenylpropanoids were stimulated by phytoplasma infection. ${ }^{15} \mathrm{~A}$ few studies have focused on the molecular mechanisms of plant reactions. Using suppressive subtraction hybridization, defense genes such as Peroxidase, Thaumatin-like protein, PR10 and Prolinerich protein, and $E E F 1 A$ protein were predicated to have an important function in a resistant jujube cultivar in response to phytoplasma infection. 3,16

On the basis of previous reports, it is clear that the responses of host plants to phytoplasma infection are complex. However, the physiological and molecular mechanisms during disease symptom development are still poorly understood. In this study, we analyzed changes in the transcriptome, proteome and phytohormone levels in response to grafting a phytoplasma-infected scion onto a susceptible cultivar of jujube. The large-scale, multi-omics data set allowed identification of jujube genes and proteins that

\footnotetext{
${ }^{1}$ College of Horticulture, Henan Agricultural University, Zhengzhou 450002, China.

Correspondence: J Feng (jcfeng@henau.edu.cn)

${ }^{2}$ These authors contributed equally to this work.

Received: 7 August 2017; Revised: 16 October 2017; Accepted: 5 December 2017
} 

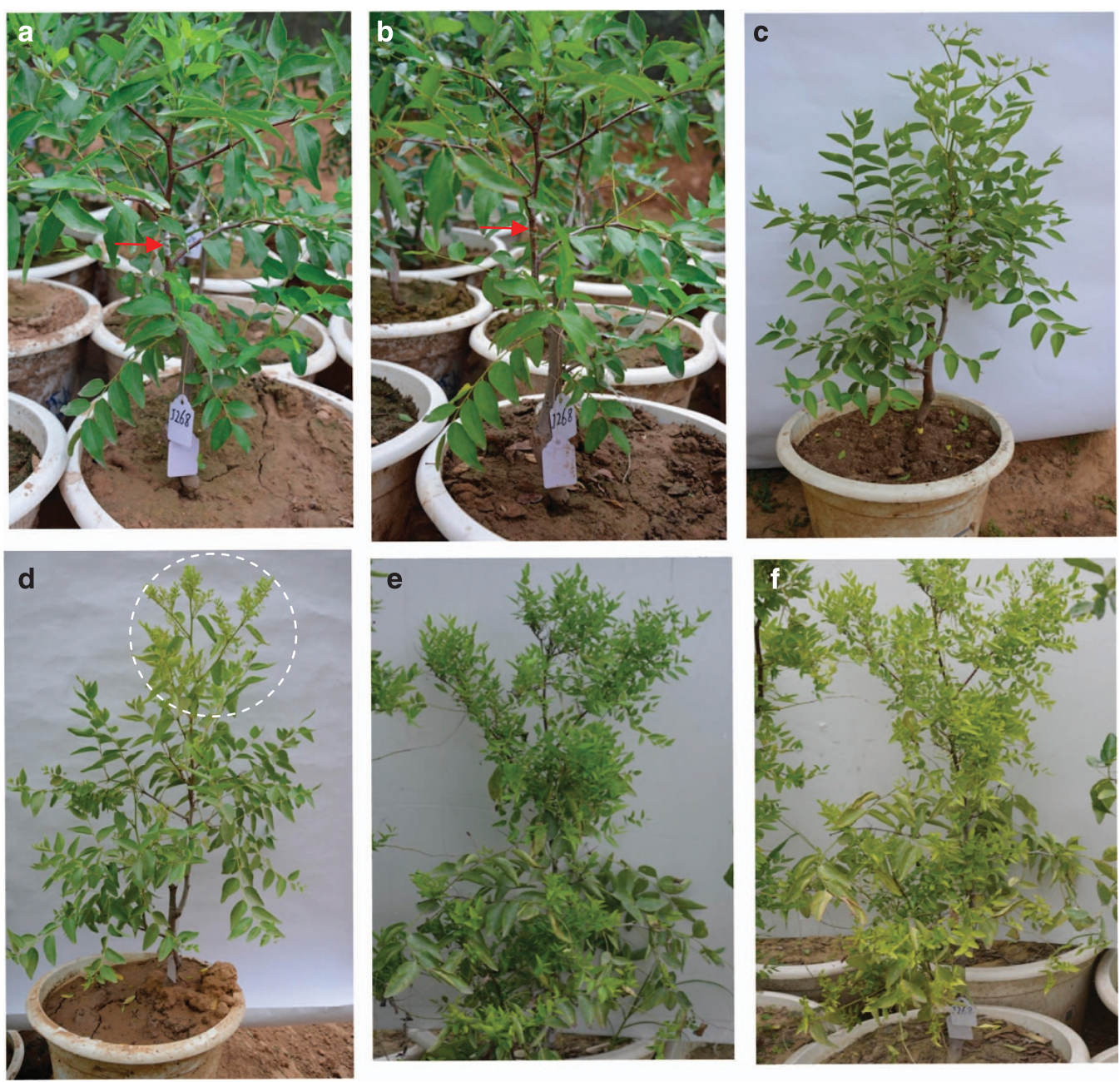

Figure 1. Symptoms of jujube infected by grafted buds carrying JWB phytoplasma at different stages. (a) Zero weeks after grafting (WAG); (b) 2 WAG; (c) 37 WAG; (d) 39 WAG; (e) 48 WAG; (f) 52 WAG. Red arrow: grafting position. The dotted circle: symptoms began to appear.

respond early to phytoplasma infection. Further, we explored the correlation between the phytoplasma-responsive transcriptome and proteome, which can serve as the foundation for further phytoplasma pathogenesis and response mechanism studies.

\section{MATERIALS AND METHODS}

\section{Plant materials}

Two-year-old jujube (Ziziphus jujuba Mill. 'Huizao') plants were grown in pots in an insect-free net-house at Henan Agricultural University, Zhengzhou, China. Leaves of each jujube plants were collected at three times during spring-summer. DNA was extracted from leaf samples using $C T A B^{17}$ for direct and nested polymerase chain reaction (PCR) using the universal phytoplasma-specific primer sets $\mathrm{P} 1 / \mathrm{P} 7$ (ref. 18) and R16F2n/ R16R2 (ref. 19) to diagnose phytoplasma infection. Jujube plants that were negative for phytoplasma infection after all three rounds of PCR examination were selected as healthy material for grafting experiments. Buds from JWB-infected adult plants (Ziziphus jujuba Mill. 'Huizao') were sampled and grafted onto healthy 2-year-old jujube plants on 13 August 2014 in the net-house. In order to analyze the migration of JWB phytoplasma within the host jujube plant, leaves were sampled every 3 days in the first month after grafting and then each week from the second month after grafting (WAG) until JWB symptoms were seen in grafted jujube plants in October 2015.

\section{PCR analysis}

$P C R$ products from the diagnosis $P C R$ using $P 1 / P 7$ (ref. 18) and R16F2n/ R16R2 (ref. 19) primers were sequenced. Primers specific to the 16S rRNA of
JWB phytoplasma were designed based on the sequencing results ( $F 1$ : CGCTAAAGTCCCCACCATTA and R1:CACATTGGGACTGAGACACG). PCR reactions contained $1 \mu \mathrm{l}$ primer mix $(0.5 \mu \mathrm{M}$ F1 and R1 JWB-specific primers), $100 \mathrm{ng}$ template DNA, $10 \mu \mathrm{L}$ PCR Master Mix (TaKaRa, Dalian, China) and purified $\mathrm{H}_{2} \mathrm{O}$ water in a total volume of $25 \mu \mathrm{L}$. Reactions were conducted using the following thermal cycling conditions: $94^{\circ} \mathrm{C}$ for $6 \mathrm{~min}$, followed by 35 cycles of denaturation for $45 \mathrm{~s}$ at $94{ }^{\circ} \mathrm{C}$, annealing for $45 \mathrm{~s}$ at $56^{\circ} \mathrm{C}$, extension for $1 \mathrm{~min}$ at $72{ }^{\circ} \mathrm{C}$ and a final extension at $72{ }^{\circ} \mathrm{C}$ for 10 min. PCR products ( $827 \mathrm{bp}$ ) were detected using $1.5 \%$ agarose gel electrophoresis.

\section{Sample collection and transcriptome analysis}

According to PCR results and symptom observation of grafted plants (Supplementary Figure S1 and Figure 1), leaf samples at six stages after grafting and from healthy plants at the same stages were collected for RNA extraction and transcriptome analysis. The six stages of infection were set at 0 WAG (13 August 2014), 2 WAG (23 August 2014), 37 WAG (27 May 2015), 39 WAG (10 June 2015), 48 WAG (13 August 2015) and 52 WAG (16 September 2015). Three trees in one replicate and three biological replicates were set, and in total nine healthy and nine infected trees were sampled in each treatment. Three or four leaves from each plant were individually collected at each stage, frozen in liquid nitrogen and then stored in $-80^{\circ} \mathrm{C}$.

For RNA extraction and transcriptome analysis, nine healthy and nine grafted plants with similarly developing characteristics were selected from more than 100 healthy and JWB-infected jujube plants for this experiment. Three samples were prepared for the following experiments. Total RNA was extracted from the above infected and healthy leaves using the RNAprep Pure Plant Kit (DP441, TianGen, Beijing, China). RNA quality and 
quantity were determined in a NanoDrop 2000c spectrophotometer (Thermo Scientific, Waltham, MA, USA), and the RNA integrity was assessed by electrophoresis in $1.0 \%$ agarose gel. Total RNA was digested with Dnase I to remove DNA. The purified RNA with an $A_{260} / A_{280}$ ratio of $1.8-2.0$ was used for transcriptome sequencing. The libraries were constructed and sequenced in an Illumina Hiseq 2500 platform.

Clean data were obtained by removing the two ends of sequences with low quality (threshold value: 30 ), removing adapter contamination and removing reads with length less than $60 \mathrm{bp}$. The resulting reads were aligned to the $Z$. jujuba genome $\mathrm{e}^{20}$ and the mapped results were then subjected to BLAST against the UniProtKB database (www.uniprot.org). Annotation information was obtained and differentially expression genes (DEGs) were screened based on having a fold change $\geqslant 2$ and a $P$ value $<0.05$.

\section{ITRAQ labeling and MS analysis}

For ITRAQ proteomics analysis, protein from the above three individual leaf samples (the same as in section 2.3) collected from healthy and diseased plants at 37 WAG and 48 WAG was extracted using SDT lysis and FASP method, ${ }^{21}$ and the detailed procedures were described as follows.

Protein extraction. The samples were ground into powder in liquid nitrogen, and then added to trichloroacetic acid (TCA)/acetone (1:9) solution by five-time volume and mixed by vortex. The mixture was placed at $-20{ }^{\circ} \mathrm{C}$ for $4 \mathrm{~h}$, and centrifuged at $6000 \mathrm{~g}$ for $40 \mathrm{~min}$ at $4{ }^{\circ} \mathrm{C}$, and then the supernatant was discarded. The precipitation was washed with precooling acetone for three times, and then air-dried. The obtained powder was added to 30 times volume of SDT buffer (4\% sodium dodecyl sulfate (SDS), $1 \mathrm{mM}$ dithiothreitol (DDT) and $100 \mathrm{mM}$ Tris- $\mathrm{HCl}, \mathrm{pH}$ 7.6), mixed and boiled for $5 \mathrm{~min}$. The lysate was sonicated and then boiled for $15 \mathrm{~min}$, followed by centrifugation at $14000 \mathrm{~g}$ for $40 \mathrm{~min}^{22}$

After the protein extraction, the protein was filtered with $0.22 \mu \mathrm{m}$ filters, and the filtrate was quantified with the bicinchonininc acid Protein Assay Kit (Bio-Rad, Hercules, CA, USA). Proteins $(20 \mu \mathrm{g})$ were mixed with $5 \times$ loading buffer boiled for $5 \mathrm{~min}$, and then separated on 10\% SDS-PAGE gel (constant current $14 \mathrm{~mA}, 90 \mathrm{~min}$ ) to detect protein purity. Protein bands were visualized with Coomassie Blue R-250 staining.

Filter-aided sample preparation (FASP Digestion). Protein solution $(30 \mu \mathrm{l})$ was taken and DTT was added to a $10 \mathrm{mM}$ final concentration, and boiled for $5 \mathrm{~min}$, and then cooled to room temperature. UA buffer $(200 \mu \mathrm{l} ; 8 \mathrm{M}$ urea, $150 \mathrm{mM}$ Tris- $\mathrm{HCl}, \mathrm{pH} 8.0$ ) was added and centrifuged at $14000 \mathrm{~g}$ for $15 \mathrm{~min}$ for two times. UA buffer ( $100 \mu \mathrm{l} ; 100 \mathrm{mM}$ iodoacetamide in UA) was added by vortex at 600 r.p.m. for $1 \mathrm{~min}$. The samples were incubated for $30 \mathrm{~min}$ in darkness, and centrifuged at $14000 \mathrm{~g}$ for $15 \mathrm{~min}$. Dissolution buffer ( $100 \mu \mathrm{l}$; AB SCIEX, Foster City, CA, USA; DS buffer) was added and centrifuged at $14000 \mathrm{~g}$ for $15 \mathrm{~min}$ for two times. Proteins for each sample were incorporated into $30 \mu \mathrm{l}$ SDT buffer. Then, $100 \mu \mathrm{l}$ iodoacetamide ( $100 \mathrm{mM}$ indole-3-acetic acid in UA buffer) was added to block reduced cysteine residues. Finally, the protein suspensions were digested with $4 \mathrm{\mu g}$ Trypsin (Promega, Madison, WI, USA) in $40 \mu \mathrm{l}$ DS buffer overnight at $37^{\circ} \mathrm{C}$ and the resulting peptides were collected as a filtrate. ${ }^{23}$ The filtrated peptides of each sample were desalted on C18 Cartridges (Empore SPE Cartridges C18, bed I.D. $7 \mathrm{~mm}$, volume $3 \mathrm{~mL}$, Sigma, St Louis, MO, USA), concentrated by vacuum centrifugation and reconstituted in $40 \mu \mathrm{L}$ of $0.1 \%$ $(\mathrm{v} / \mathrm{v})$ formic acid. The peptide content was estimated by ultraviolet light spectral density at $280 \mathrm{~nm}$ using an extinction coefficient of 1.1 of $0.1 \%$ $\left(\mathrm{g} \mathrm{L}^{-1}\right)$ solution.

ITRAQ labeling and strong cation exchange fractionation. The resulting peptide mixture from each sample was labeled using iTRAQ reagent according to the manufacturer's instructions (Applied Biosystems, Foster City, CA, USA). The leaf samples collected from healthy plants at 37 WAG and 48 WAG were labeled as respective controls.

The ITRAQ-labeled peptides were fractionated by strong cation exchange (SCX) chromatography using the AKTA Purifier system (GE Healthcare, Uppsala, Sweden) by the following steps: reconstituted and acidified the labeled peptides with buffer $\mathrm{A}\left(10 \mathrm{mM} \mathrm{KH}_{2} \mathrm{PO}_{4}\right.$ in $25 \%$ of acetonitrile, $\mathrm{pH}$ 3.0), and then loaded onto a PolySULFOETHYL $4.6 \times 100 \mathrm{~mm}$ column $(5 \mu \mathrm{m}, 200 \AA \AA$, PolyLC Inc, Colombia, MD, USA) and eluted at a flow rate of $1 \mathrm{ml} \mathrm{min}-1$ with a gradient of $0-8 \%$ buffer $B$ $\left(500 \mathrm{mM} \mathrm{KCl}, 10 \mathrm{mM} \mathrm{KH}{ }_{2} \mathrm{PO}_{4}\right.$ in $25 \%$ of acetonitrile, $\mathrm{pH} \mathrm{3.0)}$ for $22 \mathrm{~min}$, followed by $8-52 \%$ buffer B during $22-47 \mathrm{~min}, 52-100 \%$ buffer B during 47-50 min, $100 \%$ buffer $B$ during $50-58$ min and finally buffer $B$ was reset to $0 \%$ after $58 \mathrm{~min}$. The elution was monitored by measuring the absorbance at $214 \mathrm{~nm}$, and fractions were collected at every $1 \mathrm{~min}$. The eluted peptides were desalted with C18 Cartridges (Empore SPE Cartridges C18, bed I.D.7 mm, volume $3 \mathrm{~mL}$, Sigma) and concentrated by vacuum centrifugation.

Mass spectrometry. Each obtained fraction was injected for nano Liquid chromatography-mass spectrometry analysis. The peptide mixture in buffer $\mathrm{A}(0.1 \%$ formic acid) was loaded onto a reverse phase trap column (Acclaim PepMap100, $100 \mu \mathrm{m} \times 2 \mathrm{~cm}$, nanoViper C18, Thermo Scientific) connected to the C18-reversed phase analytical column (Easy Column, $10 \mathrm{~cm}$ long, $75 \mu \mathrm{m}$ inner diameter, $3 \mu \mathrm{m}$ resin, Thermo Scientific). Then, the peptide was separated with a linear gradient of buffer B $(84 \%$ acetonitrile and $0.1 \%$ formic acid) at a flow rate of $300 \mathrm{nl} \mathrm{min}^{-1}$ controlled by IntelliFlow technology. The linear gradient was: $0-35 \%$ buffer B for 50 min, $35-100 \%$ buffer B for $5 \mathrm{~min}$ and hold in $100 \%$ buffer B for $5 \mathrm{~min}$.

LC-MS/MS analysis was performed on a $Q$ Exactive mass spectrometer (Thermo Scientific). MS data were obtained from the survey scan (300$1800 \mathrm{~m} / \mathrm{z}$ ) for higher-energy-collisional dissociation fragmentation. Automatic gain control target was set to $3 \mathrm{e} 6$ and maximum inject time to $10 \mathrm{~ms}$. Dynamic exclusion duration was $40 \mathrm{~s}$. Survey scans were acquired at a resolution of 70000 at $200 \mathrm{~m} / \mathrm{z}$ and resolution for higher-energycollisional dissociation spectra was set to 17500 at $200 \mathrm{~m} / \mathrm{z}$, and isolation width was $2 \mathrm{~m} / \mathrm{z}$. Normalized collision energy was $30 \mathrm{eV}$ and the underfill ratio was defined as $0.1 \%$.

Data analysis. MS/MS spectra were searched against the UniProtKB database (www.uniprot.org) using the MASCOT engine (Matrix Science, London, UK; version 2.2) embedded into Proteome Discoverer 1.4. Relative parameters was set as follows: trypsin was chosen as the enzyme, and Carbamidomethyl (C), iTRAQ 4/8 plex (N-term) and iTRAQ 4/8 plex (K) as fixed modifications; Oxidation (M) and ITRAQ 4/8plex ( $\mathrm{Y}$ ) as variable modifications; peptide mass tolerance: $\pm 20 \mathrm{mg} / \mathrm{l}$ and fragment mass tolerance: $0.1 \mathrm{Da}$. To reduce the probability of false peptide identification (false discovery rate (FDR)), only peptides with FDR of $1 \%$ at the protein level were counted as the identified protein and each identified protein had at least one unique peptide. For protein quantification, the protein ratios are calculated as the median of only unique peptides of the protein. The thresholds of unique peptide were determined by FDR $<0.01$, and protein was considered as a differentially expressed protein (DEP) if its fold change was at least 1.2 and its $P$ value $<0.05$ (Student's $t$-test).

\section{Correlation analysis of transcriptome and proteome}

Correlation between the expression levels of a gene in the transcriptome and its corresponding protein in the proteome was evaluated using Spearman's correlation test. ${ }^{24}$ The results were divided into three categories: the same expression trend, the opposite expression trend and no expression difference.

\section{Bioinformatics analysis}

Annotation analysis of Gene Ontology (GO) was performed for the screened DEGs with the Blast2GO software (http://www.geneontology. org). Following three ontologies for $\mathrm{GO}$ annotation of DEGs were included: molecular function, cellular component and biological process. GO enrichment analysis was carried out according to all GO terms that were significantly enriched by the DEGs. For each GO term, the number of genes was calculated before the hypergeometric test to find significantly enriched $\mathrm{GO}$ terms based on the input list of DEGs. ${ }^{25}$

KEGG (Kyoto Encyclopedia of Genes and Genomes) databases (http:// www.genome.jp/kegg/pathway.html) were used to perform pathway enrichment analysis of the DEGs. ${ }^{26}$

\section{Phytohormone quantification}

The above leaf samples collected at 0 WAG, 37 WAG and 48 WAG were further analyzed for free JA and salicylic acid content using HPLC -MS/MS (high performance liquid chromatography-MS/MS) (SCIEX-6500Qtrap, Applied Biosystems, Foster City, CA, USA) as described. ${ }^{27}$ Phytohormone concentration was analyzed using SPSS 17.0 with three replications, and the Duncan's multiple range test was applied at $P=0.05$ probability level to evaluate the significant differences among treatments. 
4

Real-time PCR analysis

Complementary DNA (CDNA) sequences of DEGs were downloaded from transcriptome sequence data, and real-time PCR primers were designed by Primer Express 3.0 (ABI; Supplementary Table S1). Total RNA was reversetranscribed using PrimeScript RT reagent kit (TaKaRa), and then CDNA solution was diluted to $80-100 \mu \mathrm{L}$ according to their concentration with Rnase-free water. Real-time PCR was performed with SYBR Premix Ex Taq II kit (TaKaRa) using an ABI PRISM 7500 FAST Sequence Detection System (Applied Biosystems). Reactions of $20 \mu \mathrm{L}$ total volume contained $1 \mu \mathrm{L}$ diluted cDNA template, $2 \mu \mathrm{L}$ primers $(0.4 \mu \mathrm{M}$ each forward and reverse primer), $10 \mu \mathrm{L}$ SYBR Premix Ex Taq II solution and $7 \mu \mathrm{L}$ water. The amplification reaction was conducted at $95^{\circ} \mathrm{C}$ for $30 \mathrm{~s}, 40$ cycles of $95^{\circ} \mathrm{C}$ for $5 \mathrm{~s}, 60^{\circ} \mathrm{C}$ for $31 \mathrm{~s}$ and a final dissociation step at $95^{\circ} \mathrm{C}$ for $15 \mathrm{~s}, 60{ }^{\circ} \mathrm{C}$ for $1 \mathrm{~min}$ and $95^{\circ} \mathrm{C}$ for $15 \mathrm{~s}$. Each experiment was repeated three times with three biological replicates.

Relative expression levels of DEGs at 37 WAG infected versus noninfected scions were measured using the $\Delta \Delta C_{T}$ method, and actin gene was used as a reference gene for data normalization.

\section{RESULTS}

Transcriptome and proteome differences during early phytoplasma infection via grafting

PCR analysis (Supplementary Figure S1) was used to determine the infection stages in jujube plants receiving infected bud grafts. The transcriptome of leaf samples from these six stages after grafting indicated that the highest number of DEGs occurred at 37 WAG. Typical symptoms of JWB were observed at 48 WAG (Figure 1). Therefore, leaf samples from the above two stages were sampled for protein analysis using iTRAQ during phytoplasma infection.

Through transcriptome analysis, 25067 genes were identified at both 37 WAG and 48 WAG (Table 1). Of these, 16703 and 21367 genes were annotated in the SwissProt and TrEMBL databases, respectively. At 37 WAG, 1994 genes were significantly differentially expressed in JWB-grafted plants compared with uninfected plants, with 693 of these upregulated and 1301 of these downregulated (fold change $>2.0$ and $P$ values $<0.05$ in $t$-test (Supplementary Tables S2 and S3)). At 48 WAG, 2401 DEGs were detected, with 808 genes upregulated and 1593 genes downregulated compared with the uninfected controls (Supplementary Tables S4 and S5).

The iTRAQ analysis resulted in a total of 583908 spectra, with 41465 of these matching known peptides. Among them, 37992 unique peptides were identified, and 6748 proteins were explored. At 37 WAG, 5378 proteins were identified, and at 48 WAG 5377 were identified (Table 1). At 37 WAG, a total of 289 differentially expressed proteins (DEPs) were observed, with 176 proteins upregulated and 113 proteins downregulated compared with the uninfected control (fold change $>1.2$ and FDR $<0.01$ ). At 48 WAG, a total of 753 DEPs were detected, with 358 proteins upregulated and 395 proteins downregulated compared with the uninfected control.

Table 1. Summary of the number of proteins and mRNA detected during phytoplasma infection of Ziziphus jujuba Mill.

\begin{tabular}{|c|c|c|c|c|}
\hline \multirow[t]{2}{*}{ Category } & \multicolumn{2}{|c|}{ Proteins } & \multicolumn{2}{|c|}{ mRNAs } \\
\hline & 37 WAG & $48 W A G$ & 37 WAG & 48 WAG \\
\hline Unique protein/gene detected & 5378 & 5377 & 25067 & 25067 \\
\hline $\begin{array}{l}\text { Significantly changed proteins/ } \\
\text { genes }\end{array}$ & 289 & 753 & 1994 & 2401 \\
\hline Upregulated & 176 & 358 & 693 & 808 \\
\hline Downregulated & 113 & 395 & 1301 & 1593 \\
\hline
\end{tabular}

\section{GO analysis of DEGs and DEPs}

Of the 25067 genes identified in the transcriptome analysis, 18926 genes (75.5\%) were annotated via GO analysis. At 37 WAG the category with the most DEGs was cellular components, with 693 genes upregulated with the main functions defined as chloroplast (119 genes) and chloroplast stroma (55 genes). In the molecular function category, most of the upregulated genes were involved in metal ion binding (80 genes) and iron ion binding (29 genes). In the biological process category, 28 upregulated genes were involved in flavonoid biosynthetic process (Supplementary Table S2). Among the 1301 downregulated genes (Supplementary Table S3), 82 genes were involved in response to biotic stimulus, and more than 137 genes were involved in phytohormone regulation (Supplementary Table S3). The top hormone-related functions were auxin-activated signaling pathway (66 genes), response to SA (44 genes) and response to jasmonic acid (27 genes; Supplementary Table S3). Three genes (XLOC_013752, XLOC_013753 and XLOC_021944) related to JA O-methyltransferase activity were also downregulated (Supplementary Table S3).

At 48 WAG there were 808 upregulated genes (Supplementary Table S4). The categories with the most DEGs were cellular components, such as the 214 genes encoding integral components of the membrane, 197 genes related to the plasma membrane and 105 genes related to the plasmodesma. Among the 1593 downregulated genes (Supplementary Table S5), the cellular component category was again the most represented, such as the 342 genes involved in chloroplasts, 211 genes related to membranes and 121 genes involved in the chloroplast stroma. Together, this means that the expressions of most genes in the photosynthetic system were affected by phytoplasma infection.

At 37 WAG, 289 DEPs were classified into 43 categories according to their biological process, molecular function or cellular component (Supplementary Figure S2 and Supplementary Table S6). There were 176 proteins upregulated and 113 proteins downregulated compared with the uninfected control (fold change $>1.2$ and $P$ value $<0.05$ in $t$-test). Among the upregulated DEPs, there were four proteins with abundance changes of more than twofold, namely a JA-induced protein-like (4.38-fold, TCONS_00019449), a granule-bound starch synthase (3.29-fold, TCONS_00052666), a phosphoenolpyruvate carboxykinase-like protein (2.14-fold, TCONS_00033847) and another JA-induced protein-like (2.01-fold, TCONS_00032059; Table 2). Two of the top four DEPs were related to JA-induced protein, in which the co-expression with the JA biosynthesis enzyme (allene oxide synthase) is accompanied by a rise in JAs. ${ }^{28}$ Proteins related to flavonoid biosynthesis (1.89-fold and 1.77-fold higher) and phenylalanine metabolism pathways (1.81-fold) were also upregulated in the leaves of the infected jujube (Table 2). Of the downregulated DEPs, the one with the most change, at more than threefold, was GRF1-interaction factor 1 protein (Table 2), which is a component of the pathway controlling leaf growth by regulating cell proliferation in a transverse direction.

In leaves at 48 WAG, 753 DEPs were detected, with 358 proteins upregulated and 395 proteins downregulated compared with the uninfected control (Supplementary Figure S2 and Supplementary Table S7). Among the upregulated proteins, three of the top 10 DEPs were L-gulonolactone oxidase-like proteins (TCONS_00033106: 3.63-fold, TCONS_00033103: 2.98-fold and TCONS_00033097: 2.73-fold), which are enzymes that produce vitamin C (Table 3). Two of the top 10 upregulated proteins were JA-induced protein-like (TCONS_00032059: 3.16-fold and TCONS_00006683: 2.78-fold). Of the downregulated proteins, a more than sixfold decrease of the linoleate 13S-lipoxygenase 2-like protein (LOX2) was observed in the leaf sample at 48 WAG compared with the control, and two of the top five DEPs were JA-induced protein-like proteins (TCONS_00050299: 0.344 and 
Table 2. Summary of the top 10 DEPs at 37 WAG with phytoplasma infecting scion

\begin{tabular}{|c|c|c|c|c|}
\hline Accession $^{\mathrm{a}}$ & Sequence description & Fold change (37 WAG/CK) & KEGG term (Map name) & $\mathrm{P}$ value \\
\hline TCONS_00019449 & $23 \mathrm{kDa}$ jasmonate-induced -like & 4.38 & $\alpha$-Linolenic acid metabolism & 0.0419 \\
\hline TCONS_00052666 & Granule-bound starch synthase & 3.29 & Starch and sucrose metabolism & 0.0014 \\
\hline TCONS 00033847 & Phosphoenolpyruvate carboxykinase [ATP]-like & 2.14 & None & 0.0102 \\
\hline TCONS_00032059 & $23 \mathrm{kDa}$ jasmonate-induced -like & 2.014 & $\alpha$-Linolenic acid metabolism & 0.0083 \\
\hline TCONS_00024299 & Dihydroflavonol 4-reductase & 1.89 & Flavonoid biosynthesis & 0.0152 \\
\hline TCONS_00048113 & Phenylalanine ammonia lyase & 1.819 & Phenylalanine metabolism & 0.0124 \\
\hline TCONS_00021256 & Flavonoid 3-hydroxylase & 1.77 & Flavonoid biosynthesis & 0.0128 \\
\hline TCONS 00025885 & Aspartic proteinase nepenthesin- 2 & 1.77 & None & 0.0049 \\
\hline TCONS_00014361 & Superoxide dismutase $[\mathrm{Fe}]$ chloroplastic-like & 1.77 & MAPK signaling pathway & 0.0094 \\
\hline TCONS_00030498 & Desacetoxyvindoline 4 & 1.75 & None & 0.0012 \\
\hline TCONS_00008208 & GRF1 interaction factor 1 & 0.31 & None & 0.0020 \\
\hline TCONS_00000288 & DNA replication licensing factor MCM6-like & 0.45 & DNA replication & 0.0395 \\
\hline TCONS 00025058 & Nitrate reductase & 0.52 & Nitrogen metabolism & 0.0257 \\
\hline TCONS_00045226 & Abscisic acid receptor PYR1-like & 0.60 & MAPK signaling pathway & 0.0019 \\
\hline TCONS_00030214 & Sieve element occlusion a & 0.61 & None & 0.0302 \\
\hline TCONS_00034614 & Subtilisin-like protease-like & 0.61 & None & 0.0001 \\
\hline TCONS_00022334 & Cytochrome P450 71A1-like & 0.62 & None & 0.0054 \\
\hline TCONS_00022924 & Movement-binding isoform 1 & 0.631 & None & 0.0163 \\
\hline TCONS_00000768 & BRG-1 associated & 0.65 & None & 0.0485 \\
\hline TCONS_00009541 & $125 \mathrm{kDa}$ kinesin-related-like & 0.65 & None & 0.0039 \\
\hline
\end{tabular}

Abbreviations: DEP, differentially expressed protein; KEGG, Kyoto Encyclopedia of Genes and Genomes; MAPK, mitogen-activated protein kinase; WAG, weeks

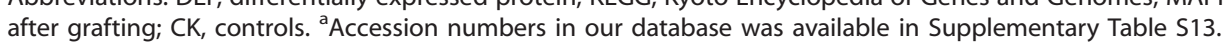

\begin{tabular}{|c|c|c|c|c|c|}
\hline TCONS_00023218 & B-cell receptor-associated 31-like & 4.08 & None & None & 0.0113 \\
\hline TCONS_00042803 & Beta expansin-like & 3.26 & None & None & 0.0062 \\
\hline TCONS_00032059 & 23 kDa jasmonate-induced-like & 3.16 & None & None & 0.0003 \\
\hline TCONS_00033103 & L-gulonolactone oxidase-like & 2.98 & None & None & 0.0022 \\
\hline TCONS_00033097 & L-gulonolactone oxidase-like & 2.73 & None & None & 0.0495 \\
\hline TCONS_00033649 & E3 ubiquitin-ligase HERC2-like & 2.66 & None & None & 0.0478 \\
\hline TCONS_00008624 & Linoleate 13S-lipoxygenase 2-like & 0.16 & Linoleic acid metabolism & K00454 & 0.0009 \\
\hline TCONS_00050299 & 23 kDa jasmonate-induced-like & 0.34 & None & None & 0.0019 \\
\hline TCONS_00028902 & Sieve element occlusion b Zeatin & 0.36 & None & None & 0.0047 \\
\hline TCONS_00015275 & O-glucosyltransferase-like & 0.36 & None & None & 0.0001 \\
\hline TCONS_00009593 & Chloroplastic/mitochondrial-like & 0.39 & None & None & 0.0109 \\
\hline TCONS_00028899 & $\begin{array}{l}\text { Sieve element occlusion a } n \text { characterized } \\
\text { protein }\end{array}$ & 0.42 & None & None & 0.0016 \\
\hline TCONS_00000655 & Ycf23-like & 0.42 & None & None & 0.0088 \\
\hline
\end{tabular}

TCONS_00019449: 0.370), which means JA was an important factor during phytoplasma infection of jujube (Table 3).

KEGG pathway analysis for DEGs and DEPs

Of the 25067 genes from the transcriptome analysis, 10104 genes $(40.3 \%)$ were annotated by KEGG analysis. At 37 WAG in plants grafted with JWB-infected scions, 20 of the upregulated genes were involved in flavonoid biosynthesis, 11 in phenylpropanoid biosynthesis and 10 genes in phenylpropanoid metabolism (Supplementary Table S8). Among the downregulated genes, the two most populated groups were related to plant-pathogen interaction and plant hormone signal transduction (Supplementary Table S9 and Supplementary Figures S3 and S4). Three to four downregulated genes were involved in plant-pathogen interactions (Table 4 and Supplementary Figure S4), with five of these genes representing two calcium-binding proteins (CML), one LRR receptor-like serine/ threonine-protein kinase (FLS2), pathogenesis-related protein 1 (PR1) and the disease resistance protein RPM1 expressed at levels eightfold lower than in the control. A total of 28 genes involved in plant hormone signal transduction were downregulated (Table 5 
Table 4. Downregulated genes' plant-pathogen interaction in KEGG pathway analysis in leaves 37 WAG with JWB-infected scions

\begin{tabular}{|c|c|c|c|c|c|c|}
\hline Gene_Id ${ }^{\mathrm{a}}$ & Value_1 & Value_2 & Log2 (fold-change) & Name & Definition & $\mathrm{P}$ value \\
\hline XLOC_008034 & 52.26 & 1.99 & -4.72 & $C M L$ & Calcium-binding protein CML & 0.00005 \\
\hline XLOC_002521 & 5.97 & 0.45 & -3.72 & FLS2 & LRR receptor-like serine/threonine-protein kinase FLS2 & 0.00005 \\
\hline XLOC_016194 & 63.57 & 5.81 & -3.45 & $C M L$ & Calcium-binding protein CML & 0.00005 \\
\hline XLOC_016016 & 100.55 & 10.81 & -3.22 & $P R 1$ & Pathogenesis-related protein 1 & 0.00005 \\
\hline XLOC_020804 & 2.59 & 0.30 & -3.10 & RPM1, RPS3 & Disease resistance protein RPM1 & 0.00165 \\
\hline XLOC_016017 & 36.10 & 4.53 & -2.99 & $P R 1$ & Pathogenesis-related protein 1 & 0.0001 \\
\hline XLOC_018443 & 7.80 & 1.25 & -2.64 & CNGF & Cyclic nucleotide-gated channel, other eukaryote & 0.00145 \\
\hline XLOC_012207 & 26.92 & 4.42 & -2.61 & $C P K$ & Calcium-dependent protein kinase & 0.00005 \\
\hline XLOC_001631 & 54.77 & 9.31 & -2.56 & EFR & LRR receptor-like serine/threonine-protein kinase EFR & 0.00005 \\
\hline XLOC_003968 & 7.321 & 1.35 & -2.44 & FLS2 & LRR receptor-like serine/threonine-protein kinase FLS2 & 0.0007 \\
\hline XLOC_008782 & 6.29 & 1.31 & -2.27 & RPM1, RPS3 & Disease resistance protein RPM1 & 0.0047 \\
\hline XLOC_020805 & 15.46 & 3.27 & -2.25 & RPM1, RPS3 & Disease resistance protein RPM1 & 0.00005 \\
\hline XLOC_007998 & 71.01 & 15.09 & -2.24 & $C M L$ & Calcium-binding protein CML & 0.00005 \\
\hline XLOC_012794 & 500.26 & 117.36 & -2.099 & CETN1 & Centrin-1 & 0.00005 \\
\hline XLOC_021743 & 18.13 & 4.396 & -2.06 & FLS2 & LRR receptor-like serine/threonine-protein kinase FLS2 & 0.00005 \\
\hline XLOC_002411 & 131.83 & 33.30 & -1.99 & $C M L$ & Calcium-binding protein $\mathrm{CML}$ & 0.0018 \\
\hline XLOC_004660 & 10.98 & 2.82 & -1.97 & ERF1 & Ethylene-responsive transcription factor 1 & 0.00295 \\
\hline XLOC_014256 & 157.32 & 42.25 & -1.90 & $C M L$ & Calcium-binding protein $\mathrm{CML}$ & 0.00005 \\
\hline XLOC_016219 & 3.79 & 1.102 & -1.78 & FLS2 & LRR receptor-like Serine/threonine-protein kinase FLS2 & 0.00255 \\
\hline XLOC_017988 & 48.81 & 15.31 & -1.68 & $C M L$ & Calcium-binding protein CML & 0.00005 \\
\hline Gene_Id & Value_1 & Value_2 & Log2 (fold-change) & Name & Definition & $\mathrm{P}$ value \\
\hline XLOC_019723 & 29.87 & 9.43 & -1.67 & CALM & Calmodulin & 0.0003 \\
\hline XLOC_022437 & 141.01 & 44.59 & -1.67 & SERK1 & Somatic embryogenesis receptor kinase 1 & 0.00005 \\
\hline XLOC_007823 & 48.72 & 15.44 & -1.66 & $C M L$ & Calcium-binding protein $\mathrm{CML}$ & 0.0018 \\
\hline XLOC_020251 & 14.76 & 4.83 & -1.62 & RPS2 & Disease resistance protein RPS2 & 0.00005 \\
\hline XLOC_007197 & 18.94 & 6.32 & -1.58 & EDS1 & Enhanced disease susceptibility 1 protein & 0.00005 \\
\hline XLOC_015508 & 105.62 & 36.09 & -1.55 & SERK1 & Somatic embryogenesis receptor kinase 1 & 0.00005 \\
\hline XLOC_007196 & 64.03 & 22.91 & -1.48 & EDS1 & Enhanced disease susceptibility 1 protein & 0.00005 \\
\hline XLOC_011916 & 11.73 & 4.25 & -1.46 & EFR & LRR receptor-like Serine/threonine-protein kinase EFR & 0.00015 \\
\hline XLOC_003222 & 7.10 & 2.93 & -1.28 & PBS1 & Serine/threonine-protein kinase PBS1 & 0.0061 \\
\hline XLOC_022668 & 3.95 & 1.65 & -1.26 & $\mathrm{RBOH}$ & Respiratory burst oxidase & 0.00495 \\
\hline XLOC_012474 & 30.53 & 14.37 & -1.09 & $C M L$ & Calcium-binding protein CML & 0.00165 \\
\hline XLOC_018434 & 23.35 & 11.01 & -1.09 & WRKY33 & WRKY transcription factor 33 & 0.00125 \\
\hline XLOC_008767 & 157.13 & 77.49 & -1.02 & EDS1 & Enhanced disease susceptibility 1 protein & 0.0013 \\
\hline XLOC_006178 & 1.95 & 0 & None & CERK1 & Chitin elicitor receptor kinase 1 & 0.00005 \\
\hline
\end{tabular}

Abbreviations: DEP, DEP, differentially expressed protein; KEGG, Kyoto Encyclopedia of Genes and Genomes; JWB, Jujube witches' broom; WAG, weeks after

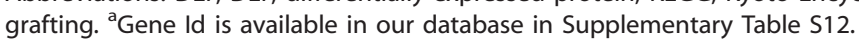

and Supplementary Figure S-3), with 11 of these genes related to tryptophan metabolism.

At 48 WAG in plants grafted with JWB-infected scions, among the upregulated genes, 16 of the upregulated genes were related to phenylpropanoid biosynthesis and 13 to flavonoid biosynthesis (Supplementary Table S10). Among the downregulated genes at 48 WAG, 74 genes were related to ribosome, 34 genes to carbon metabolism and 24 genes to photosynthesis (Supplementary Table S11).

To further investigate the plant reaction to JWB infection, potential biological functions of 289 DEPs from the 37 WAG sample and 753 DEPs from 48 WAG were identified by searching the sequences against the KEGG database. The 289 DEPs from 37 WAG were assigned to 131 KEGG pathways, and the top five pathways with the highest richFactor (numbers of enriched DEPs/ annotated proteins in pathway) were phenylpropanoid biosynthesis, biosynthesis of amino acids, starch and sucrose metabolism, phenylalanine metabolism and flavonoid biosynthesis (Figure 2a). The 753 DEPs from 48 WAG were assigned to 195 KEGG pathways, and the DEPs with the highest richFactor were those involved in carbon metabolism, biosynthesis of amino acids and carbon fixation in photosynthetic organisms (Figure 2b).

Correlation analysis between transcriptome and proteome data In the leaf samples at 37 WAG, 1367 genes/proteins were correlated in the detected 5378 proteins and 9753 transcripts (with relative expression value $>0$ in both healthy leaf and diseased leaf samples; Table 6). Among the DEGs/DEPs in the leaf samples at 37 WAG, 70 DEPs showed no corresponding genes in the transcript data and 299 DEGs showed no corresponding proteins in the proteome data (Table 6). Fourteen DEGs/DEPs showed similar expression trends, and most of these were involved in flavonoid biosynthesis, phenylalanine metabolism and phenylpropanoid biosynthesis (Figure 3a).

Of the detected 5377 proteins and 9744 transcripts from leaf samples at 48 WAG, the changes in 1377 genes/proteins were found to be correlated (Table 6). There were 210 DEPs with no corresponding genes in the transcript data, and 377 DEGs with no corresponding proteins in the proteome data (Table 6). Most of 98 DEGs/DEPs with the similar expression trend in the correlation analyses were involved in carbon metabolism, carbon fixation in photosynthetic organisms and photosynthesis (Figure $3 \mathrm{~b}$ ).

Auxin and JA content analysis

According to the transcriptome and proteome analysis, 11 DEGs were related to tryptophan metabolism and the two mostchanged DEPs were related to JA-induced protein-like in the leaf samples at 37 WAG. Therefore, the auxin and JA contents were analyzed in the control and diseased leaf samples. The results indicated that phytoplasma infection resulted in reduced auxin content and increased JA content at the early stage of JWB disease (Figure 4). Auxin content in the diseased leaf samples decreased 


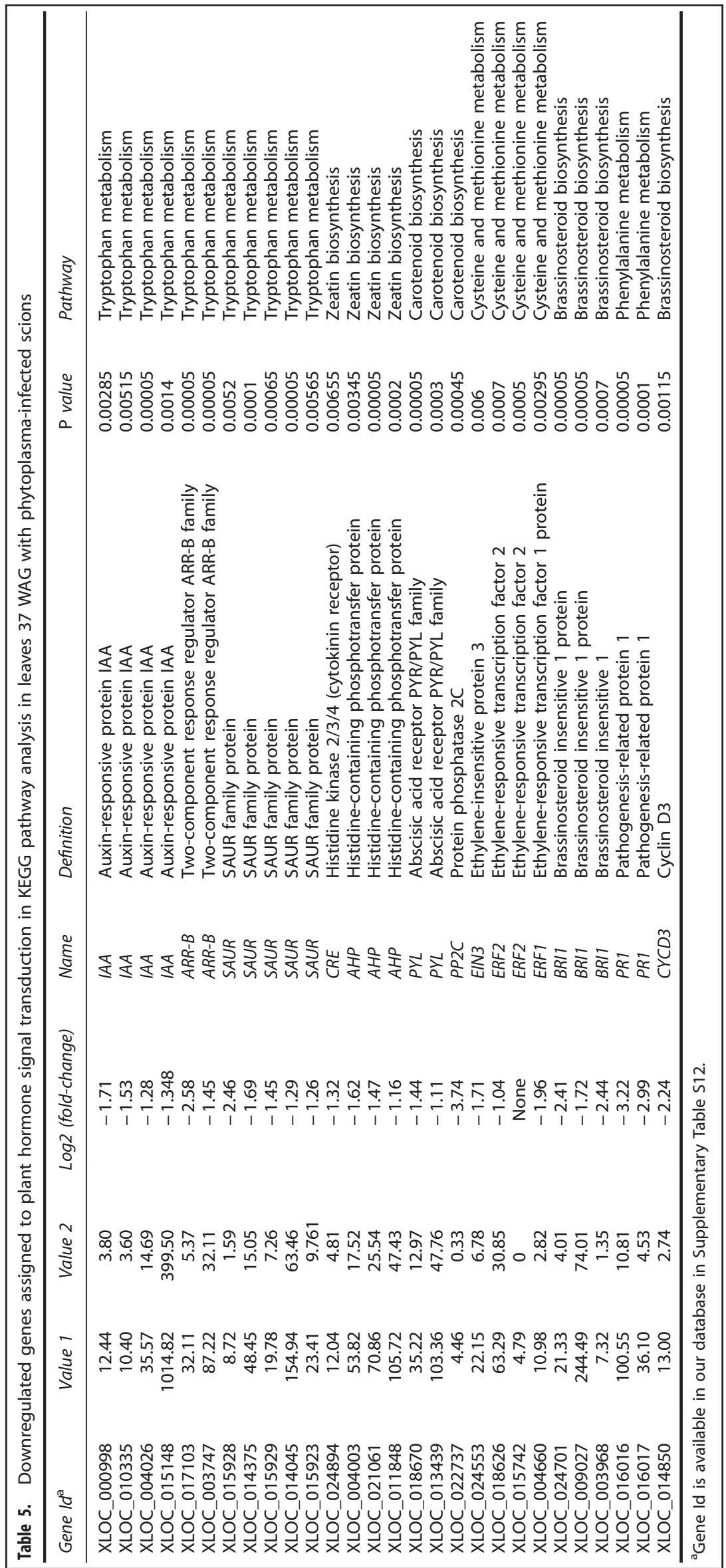




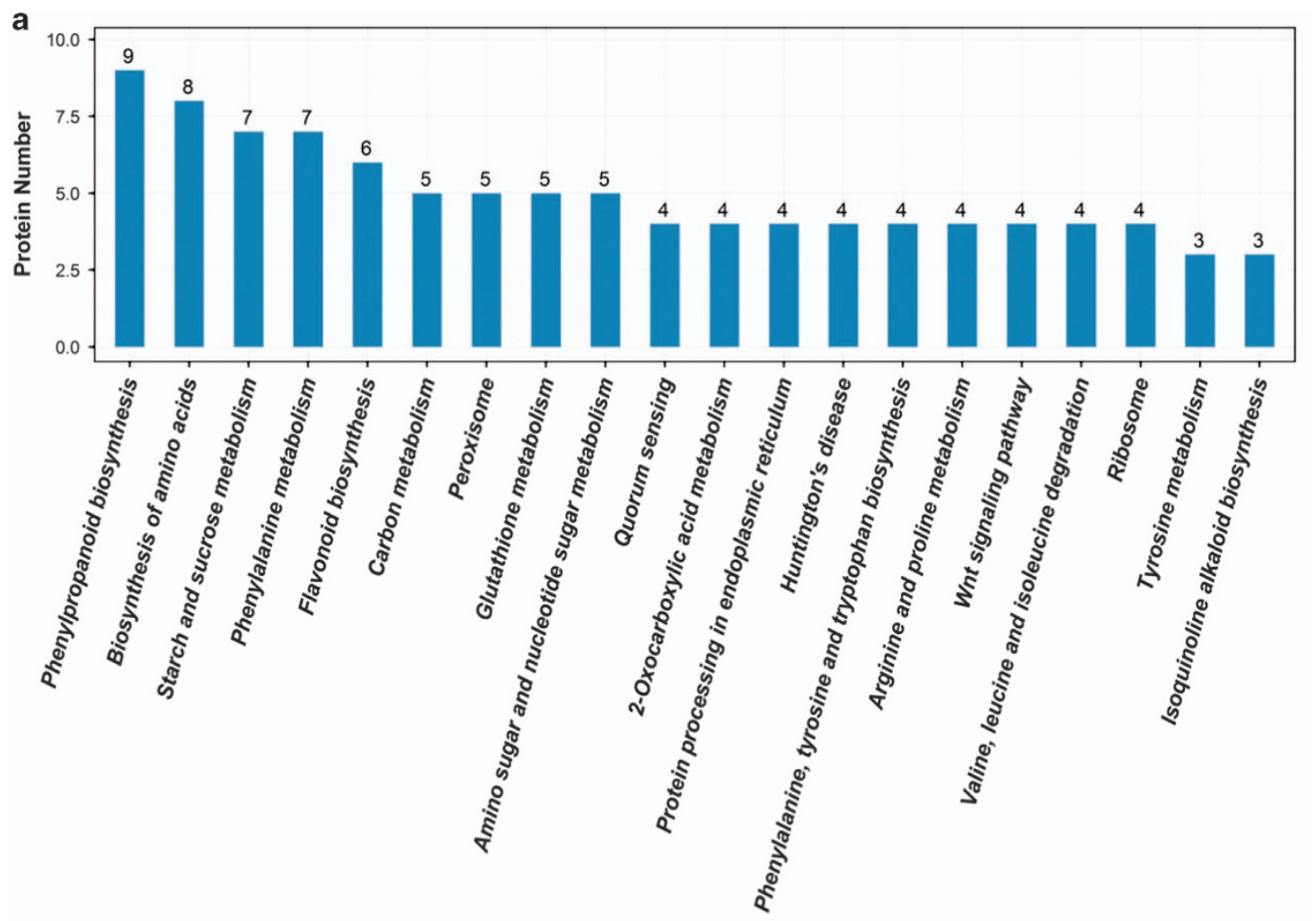

KEGG Pathways (Top 20)

b

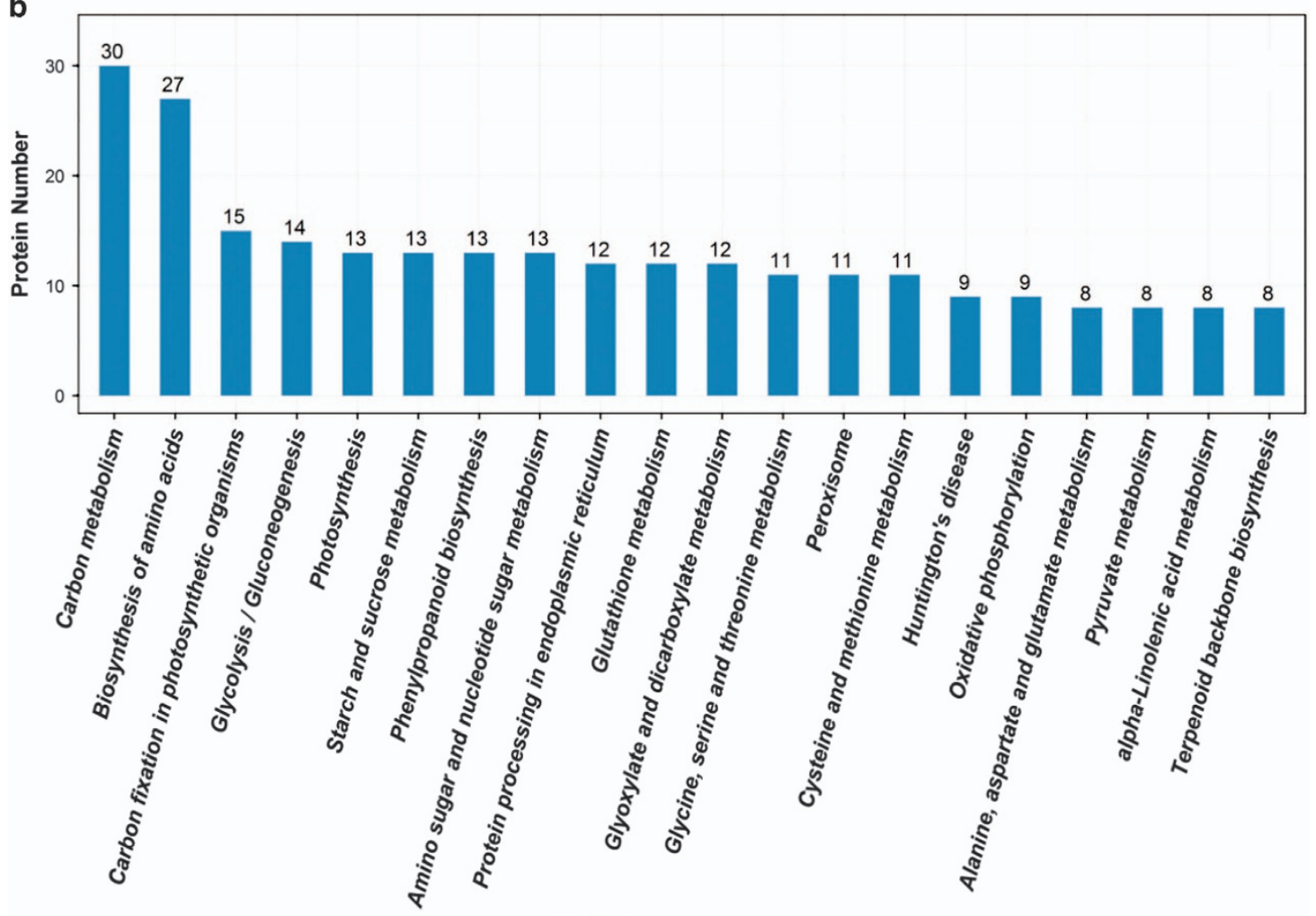

KEGG Pathways (Top 20)

Figure 2. The top 20 enriched KEGG pathways based on DEPs in leaves of jujube during JWB phytoplasma infection. (a) 37 WAG infected versus noninfected scions; (b) 48 WAG infected versus noninfected scions. 
Table 6. Correlation of DEGs and DEPs detected during phytoplasma infection of Z. jujuba Mill.

\begin{tabular}{|c|c|c|}
\hline Category & 37 WAG & $48 W A G$ \\
\hline Total numbers of detected transcripts ${ }^{a}$ & 9753 & 9744 \\
\hline Total numbers of detected protein & 5378 & 5377 \\
\hline Numbers of correlated genes/proteins & 1367 & 1377 \\
\hline $\begin{array}{l}\text { Shared DEPs/DEGs with the similar expression } \\
\text { trend }\end{array}$ & 14 & 98 \\
\hline $\begin{array}{l}\text { Shared DEPs/DEGs with the opposite expression } \\
\text { trend }\end{array}$ & 23 & 12 \\
\hline DEPs with no corresponding DEGs & 70 & 210 \\
\hline DEGs with no corresponding DEPs & 299 & 377 \\
\hline \multicolumn{3}{|c|}{ 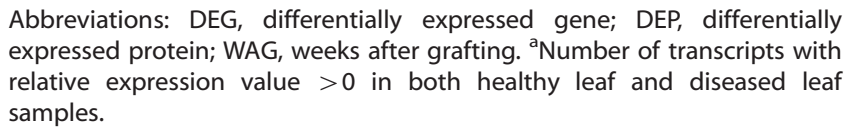 } \\
\hline
\end{tabular}

by 2.5 -fold compared with the control sample; however, there was no difference in auxin content at 48 WAG between the infected jujube and the corresponding control (Figure 4a). The JA content was higher in the infected jujube at both 37 and 48 WAG, although the amplitudes were different. The JA content in the leaf samples at 37 WAG was more than five times than that in the control; however, there was not a significant difference in JA content between the infected and control samples at 48 WAG (Figure 4b).

\section{Confirmation of qRT-PCR}

In order to evaluate our transcriptome-sequencing data, $10 \mathrm{DEGs}$ in the tryptophan metabolism pathway were selected for quantitative reverse transcriptase PCR (qRT-PCR). The results of qRT-PCR and the transcriptome-sequencing analyses indicated that all tested 10 DEGs showed similar trends in the relative expression levels (Figure 5). For instance, log2 fold change of relative expression levels from XLOC_000998 gene was close to - 1.7 in both qRT-PCR and transcriptome-sequencing data, which suggested that the gene expression changes detected by transcriptome-sequencing analysis were reliable.

\section{DISCUSSION}

Genes or proteins involved in phenylpropanoid biosynthesis or metabolism were upregulated in the early stages after JWB phytoplasma infection

Phenylpropanoid compounds are induced in response to microbial attack and can inhibit the growth of attacking pathogens. ${ }^{29}$ Phenylpropanoids include lignins, flavonoids and phenolic compounds that are products of multiple branches of the phenylpropanoid pathway. ${ }^{29,30}$ In the transcriptome of paulownia infected with witches' broom phytoplasma, numerous phenylpropanoid metabolism genes were upregulated, including phenylalanine ammonia lyase (PAL), cinnamate 4-hydroxylase and 4-coumarateCoA ligase. ${ }^{30}$ In our study, 22 genes involved in phenylpropanoid biosynthesis or metabolism were upregulated in the diseased leaf sample at 37 WAG compared with the uninfected control. For instance, expression levels of PAL (XLOC_022321) cinnamoyl-CoA reductase (XLOC_001983) and caffeoyl shikimate esterase (XLOC_003432) were significantly higher than those in the control (Supplementary Tables S8 and S12). This differential expression correlated to the change at 37 WAG in the protein level of PAL (TCONS_00048113) in infected leaves compared with the control (Table 4), which further verifies that phenylpropanoid compounds have important roles in the defense against phytoplasma infection.
Flavonoids are a diverse group of phenolic secondary metabolites and have important roles in plant defenses against both abiotic and biotic stresses. ${ }^{29}$ Flavonoids can function as passive or inducible barriers, and both flavonoid content and expression of genes in the flavonoid biosynthesis pathway increase in response to pathogen attack. $^{31,32}$ In previous transcriptome analyses of phytoplasma infection, flavonoid metabolism-related genes are activated in phytoplasma-infected plants. ${ }^{30,33}$ In our study, more than 20 genes involved in flavonoid biosynthesis were upregulated in the diseased leaf sample at 37 WAG compared with the control. For instance, the relative expression of flavonoid 3'-monooxygenase (XLOC_008694) and anthocyanidin reductase (XLOC_000417) were roughly eight times higher than those in the control (Supplementary Table S8 and Supplementary Table S12). The enzymes dihydroflavonol 4-reductase (TCONS_00024299) and flavonoid 3-hydroxylase (TCONS_00021256), both involved in flavonoid biosynthesis, were also upregulated (Table 2), which further supports that flavonoid biosynthesis has a role in early defense responses against biotic stress. ${ }^{32}$

Genes involved in tryptophan metabolism and auxin production and signaling were downregulated in the early stages after JWB phytoplasma infection

Auxin imbalance has been suggested as a key factor in the development of symptoms during phytoplasma infection. ${ }^{14}$ For example, levels of indole-3-acetic acid are reduced in mulberry infected with mulberry dwarf phytoplasma. ${ }^{34}$ Furthermore, spraying of 1-naphthaleneacetic acid on periwinkle infected with phytoplasma accelerated symptom development, which led to the conclusion that auxin may suppress expression of genes such as PATHOGENESIS-RELATED 1 in phytoplasma-infected plants and thus allow more rapid symptom development. ${ }^{14}$ In contrast, when in vitro-grown periwinkle shoots infected with 'Candidatus Phytoplasma' were treated with IAA and indole-3-butyric acid, both auxins induced recovery of phytoplasma-infected periwinkle, which implies that auxin may delay some species of phytoplasma. ${ }^{35}$ This result was further verified when pretreatment of 1-naphthaleneacetic acid also effectively enhanced plant resistance against phytoplasma. ${ }^{14}$ In addition, the phytoplasma virulence factor TENGU was found to repress auxin response factor 6 (ARF6) and ARF8, which then resulted in downregulation of auxin levels. ${ }^{10}$

In this study, 12 genes related to auxin signaling were downregulated at 37 WAG (Table 5), and auxin content declined by 2.5 -fold in the phytoplasma-infected leaf samples compared with the control (Figure 4a). At 48 WAG, when typical JWB phytoplasma symptoms were visible, there were no significant differences in the relative expression of genes related to auxin signaling or in auxin content. These results implied that auxin imbalance was a key factor in the early, but not later, stages of JWB phytoplasma infection.

Levels of JA-induced proteins and JA were altered during JWB phytoplasma infection

The activation of phytohormone signaling pathways is a universal defense response employed by plants in response to biotic or abiotic stress, ${ }^{36}$ and $\mathrm{JA}$ has central roles in regulating plant responses to herbivorous insects and microbial pathogens. ${ }^{37,38}$ For example, when Nicotiana attenuata is attacked by $M$. sexta larvae, there is a sustained JA burst ninefold above control levels. ${ }^{36}$ Fusarium oxysporum pathogens appear to utilize JAs as effectors, promoting both infection in roots and development of symptoms in shoots. ${ }^{39}$ In the Arabidopsis plants infected by AY-WB phytoplasma, the secreted AY-WB protein 11 (SAP11) is an effector that interferes with JA biosynthesis by binding and destabilizing class II CIN-TCP (CINCINNATA-RELATED-TEOSINTE BRANCHED1, CYCLOIDEA, PCF) transcription factors, which normally act as positive regulators of the LOX2 gene involved in JA 


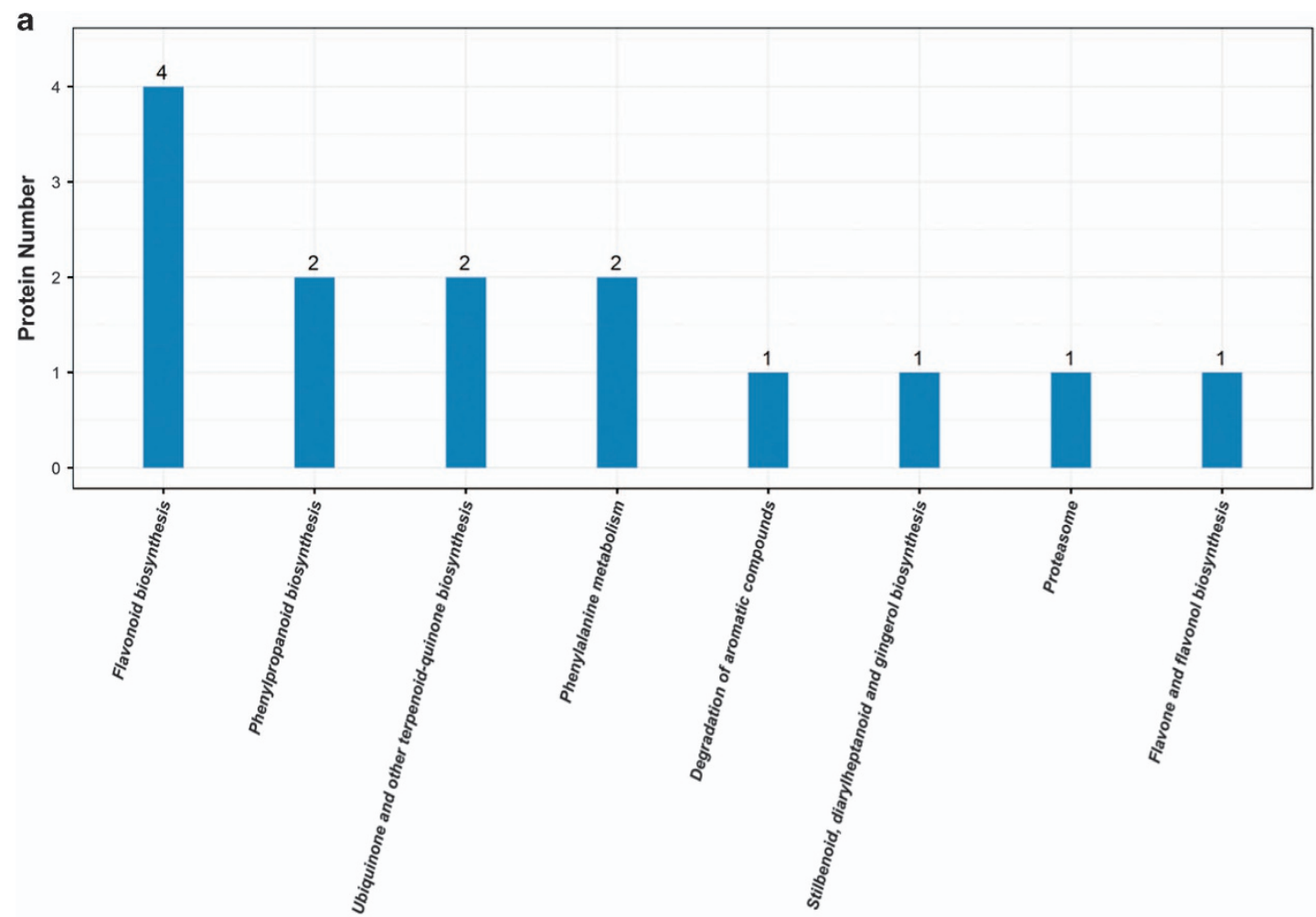

KEGG Pathways

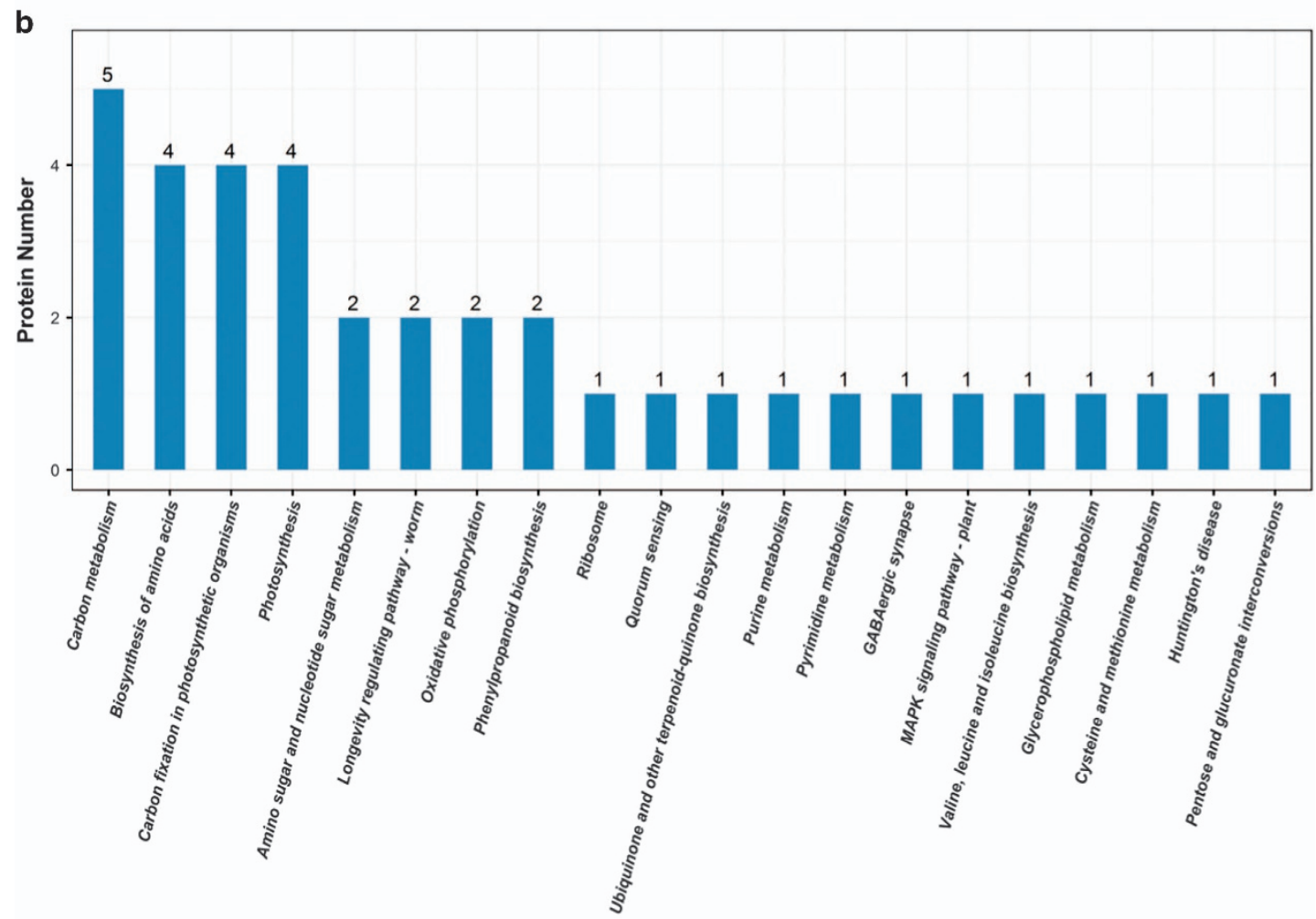

KEGG Pathways (Top 20)

Figure 3. KEGG analyses of DEPs and DEGs with the same expression trend during phytoplasma infection in Ziziphus jujuba Mill. 'Huizao'. (a) 37 WAG; (b) 48 WAG. 
a

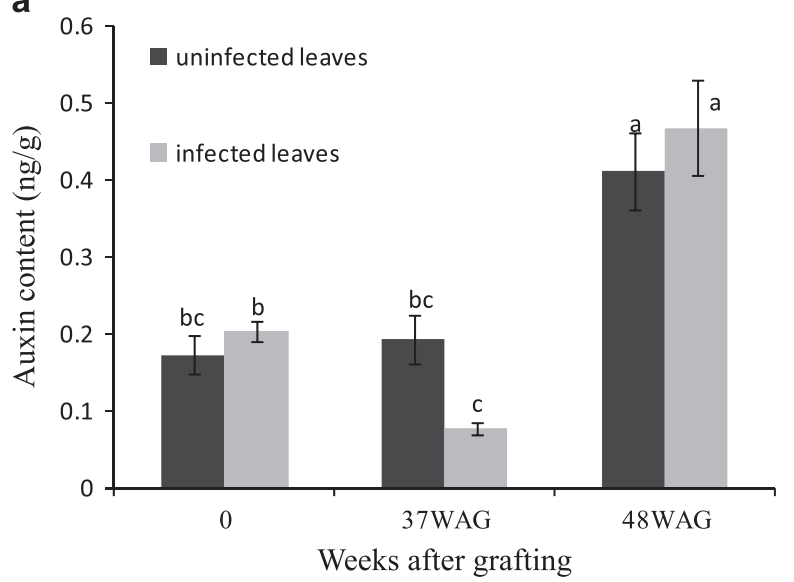

b

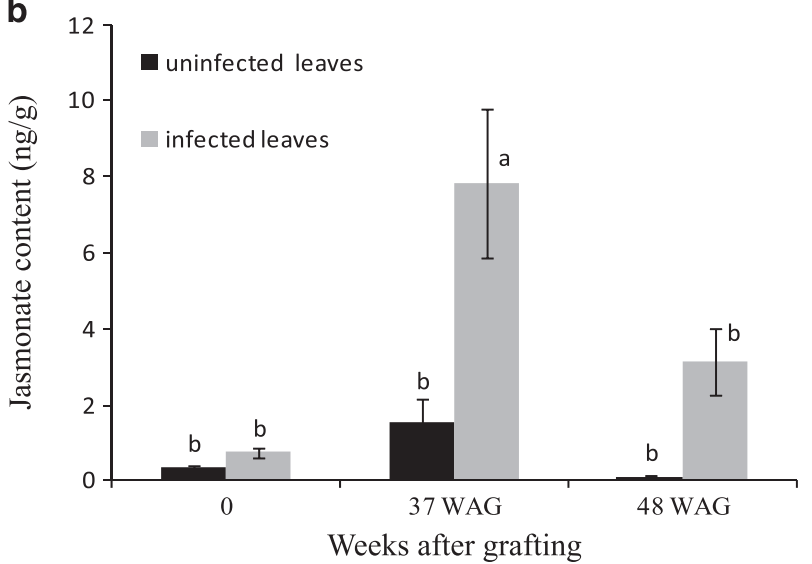

Figure 4. Auxin and jasmonate content in leaf samples 37 and 48 WAG with JWB phytoplasma-infected scions. (a) Auxin content; (b) Jasmonate content. Letters at same time point indicate differences between infected and uninfected jujube leaves.

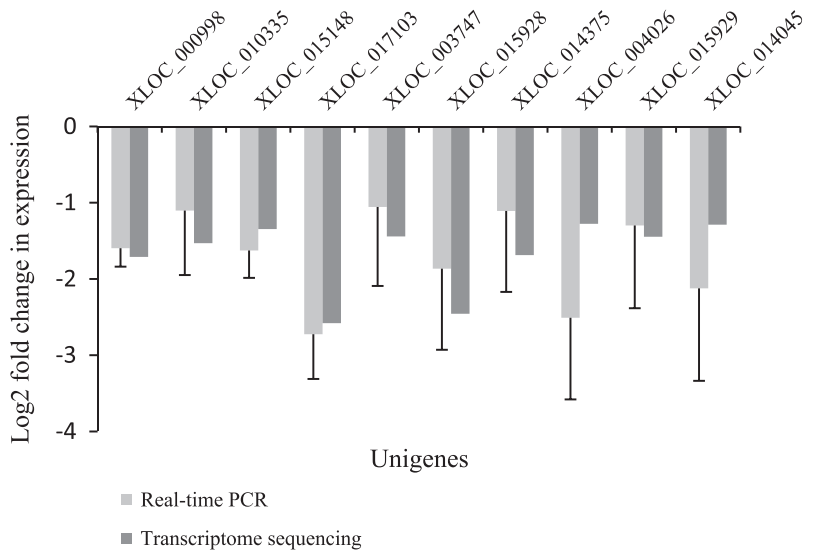

Figure 5. Real-time PCR validation of the relative expression levels of 10 DEGs in the diseased and control leaves at 37 WAG. Expression profiles of selected genes as determined by real-time PCR (grey) and transcriptome sequencing (dark grey). Relative expression of each transcript was normalized using Actin gene. The $y$ axis shows the normalized expression level of the transcript. The $x$ axis indicates genes. Error bars represent the s.d.'s of real-time PCR signals.

biosynthesis. ${ }^{40}$ Moreover, the SAP54 effector produced by AY-WB phytoplasma ${ }^{6}$ and the TENGU effector produced by onion yellows phytoplasma ${ }^{10}$ were also found to regulate both JA biosynthesis and levels in phytoplasma-infected plants. All the above research indicates that $\mathrm{JA}$ regulation has a vital part in response to herbivorous insects and microbial pathogens.

In our results at 37 WAG, two proteins (TCONS_00019449 and TCONS_00032059, Table 2) involved in a-linolenic acid metabolism as well as JA levels were significantly induced compared with the corresponding levels in the control (Table 2, Figure 4). In our experimental design, 37 WAG occurred in the spring following infection by JWB phytoplasma as new leaves were emerging. At this point, typical disease symptoms were not yet observed in the jujube plants, which implied that upregulation of JA-induced proteins and JA levels had an important part in defending against JWB phytoplasma infection at the early stage.

However, JA levels began to decrease after 37 WAG and consistently declined until 52 WAG (data not shown). There was no significant difference in JA accumulation at 48 WAG between the infected and uninfected jujube plants, when the typical JWB phytoplasma symptoms occurred (Figures 1 and 4). Furthermore, the expression level of linoleate 13S-lipoxygenase 2-like protein, which encodes a key JA biosynthesis enzyme, was six times lower than in the control, and two JA-induced proteins (TCONS_00050299 and TCONS_00019449, which were upregulated at 37 WAG) were downregulated at 48 WAG. These results further verified the tendency that JA biosynthesis and JA levels are disrupted during phytoplasma infections, and that this disruption may be beneficial for increased colonization by the phytoplasmas. ${ }^{10}$

A hypothetical working process after JWB phytoplasma infection Two models of innate immunity have been reported in plants. ${ }^{41,42}$ In one model, resistance is triggered by microbe-associated molecular patterns and is referred to as pattern-triggered immunity. In the second model, dubbed effector-triggered immunity, the plant response is triggered by pathogen effectors. ${ }^{40}$ In plants, one of the best-studied pattern-triggered immunity systems is perception of the bacterial flagellin or the flg22 peptide by FLAGELLINSENSING 2 (FLS2). ${ }^{43-45}$ Upon perception, the receptor kinase FLS2 mediates initiation of flg22-signaling responses, which contributes to bacterial growth restriction. ${ }^{43-45}$

Although several effectors, such as SAP11, SAP54 and TENGU, were verified in plants infected by phytoplasmas, ${ }^{6,10,40}$ we have not yet identified any of these above effectors in jujube plants infected with JWB phytoplasma by homologous cloning. However, four receptor kinase FLS2 genes were downregulated at 37 WAG (Table 4), which implied that FLS2/flg22 perception within the pattern-triggered immunity system may exist in the jujubephytoplasma interaction. From this, we developed a hypothetical working process in which JWB phytoplasma first produces a flg22like effector after invading jujube plants (the primary stage, Figure 6) that can be perceived by FLS2. However, by 37 WAG, expression levels of the FLS2-like receptors were downregulated in order to mediate perception of flg22-like effector to inhibit colonization of jujube with JWB phytoplasmas (the secondary stage: defense stage, Figure 6). Moreover, JA-related proteins and JA content in leaf samples were increasing, auxin-related genes and content were decreasing and DEGs involved in plantpathogen interaction and phenylpropanoid biosynthesis or metabolism were downregulated and upregulated, respectively, in the secondary stage. After pathogen recognition, the mitogenactivated protein kinases were activated, followed by regulated expression of transcription factors such as WRKY33. Other related defense genes were further regulated in the third stage (Supplementary Figure S4, Table 4 and Figure 6). In addition, typical JWB symptoms were observed in the sensitive jujube genotype when JA-related proteins and content were decreasing and DEGs involved in photosynthesis were downregulated, which would allow colonization of the jujube plants with JWB phytoplasma. 


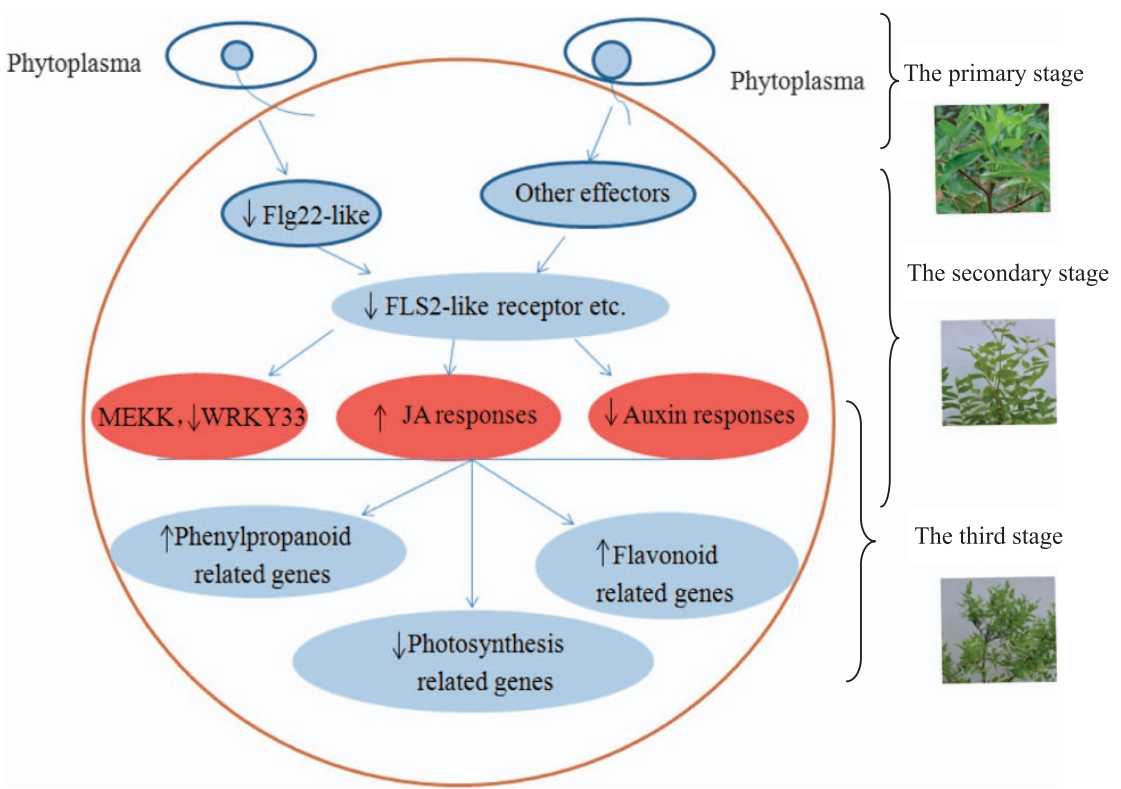

Figure 6. A hypothetical working process after JWB phytoplasma infection. During the primary stage, the phytoplasma is invading the plant and early perception has been activated. Phytoplasma gene could be detected by PCR. By the secondary stage the plant has mounted its defense response. JA-related proteins and JA levels are increasing, whereas auxin-related genes and levels are decreasing. There is a general downregulation of genes involved in plant-pathogen interaction and upregulation of genes involved in phenylpropanoid biosynthesis or metabolism. In the third stage, symptoms appear in the sensitive phenotype, concomitant with decreases in JA-related proteins and JA levels and photosynthesis-related genes. $\uparrow$ represented upregulation, $\downarrow$ represented downregulation.

\section{CONCLUSIONS}

To understand the responses and defenses of jujube plants to phytoplasma infection, a multi-omics analysis of transcriptome, proteome and phytohormone levels was conducted during JWB infection. Our results indicated that an increase in the number of DEGs occurred by 37 WAG, but that JWB typical symptoms were not observed until 48 WAG.

At 37 WAG, 1994 genes were significantly differentially expressed. Among the upregulated genes at 37 WAG, 20 genes were assigned to flavonoid biosynthesis and 21 to phenylpropanoid biosynthesis and metabolism. Among the downregulated genes, the top two groups were related to plant-pathogen interaction and plant hormone signal transduction. At 37 WAG, 289 DEPs were observed. Among the upregulated DEPs at 37 WAG were proteins related to JA-induced protein, flavonoid biosynthesis and phenylalanine metabolism. Fourteen DEGs/DEPs were shown to share similar expression trends by correlation analyses, and most of these were involved in flavonoid biosynthesis, phenylalanine metabolism and phenylpropanoid biosynthesis. Moreover, phytoplasma infection resulted in reduced auxin content and increased JA content during the early stage of phytoplasma infection.

At 48 WAG, 2401 DEGs were detected. Among the 808 upregulated genes, many were involved in phenylpropanoid biosynthesis and flavonoid biosynthesis. Among the 1593 downregulated genes, most were related to photosynthesis and carbon metabolism. At 48 WAG, 753 DEPs were detected. Of the 395 downregulated proteins, LOX2 were decreased by sixfold, and two JA-induced proteins were greatly reduced. Moreover, DEPs involved in carbon metabolism, biosynthesis of amino acids and carbon fixation in photosynthetic organisms were also downregulated. At 48 WAG, most of 98 DEGs/DEPs of similar expression trends in the correlation analyses were involved in carbon metabolism, carbon fixation in photosynthetic organisms and photosynthesis.

\section{CONFLICT OF INTEREST}

The authors declare no conflict of interest.

\section{ACKNOWLEDGEMENTS}

We thank Anita K Snyder for critical reading of the manuscript. The work was finished in Henan Provincial Key Laboratory of Fruit and Cucurbit Biology and supported by Major Science and Technology Project in Henan Province (151100110900).

\section{REFERENCES}

1 Ma C, Ye X, Chen Y, Feng J, Shang X, Li J. Anatomical observations of adventitious bud regeneration from leaf explants of Ziziphus jujuba Mill. 'Huizao'. Hort Environ Biotechnol 2012; 53: 316-319.

2 Lee S, Kim CE, Cha B. Migration and distribution of graft-inoculated jujube witches'-broom phytoplasma within a Cantharanthus roseus plant. Plant Pathol J 2012; 28: 191-196.

3 Liu ZG, Wang Y, Xiao J, Zhao J, Liu MJ. Identification of genes associated with phytoplasma resistance through suppressive subtraction hybridization in Chinese jujube. Physiol Mol Plant Pathol 2014; 86: 43-48.

4 Strauss E. Phytoplasma research begins to bloom. Science 2009; 325: 388-390.

5 Streten C, Gibb KS. Phytoplasma diseases in sub-tropical and tropical Australia. Aust Plant Pathol 2006; 35: 129-146.

6 MacLean AM, Sugio A, Makarova OV, Findlay KC, Grieve VM, Toth R. Phytoplasma effector SAP54 induces indeterminate leaf-like flower development in Arabidopsis plants. Plant Physiol 2011; 157: 831-841.

7 Sugio A, Kingdom HN, MacLean AM, Grieve VM, Hogenhout SA. Phytoplasma protein effector SAP11 enhances insect vector reproduction by manipulating plant development and defense hormone biosynthesis. Proc Natl Acad Sci USA 2011a; 108: 1254-1263.

8 Sugio A, Maclean AM, Kingdom HN, Grieve VM, Manimekalai R, Hogenhout SA. Diverse targets of phytoplasma effectors: from plant development to defense against insects. Annu Rev Phytopathol 2011b; 49: 175-195.

9 Sugio A, Hogenhout SA. The genome biology of phytoplasma: modulators of plants and insects. Curr Opin Microbiol 2012; 15: 247-254.

10 Minato N, Himeno M, Hoshi A, Maejima K, Komatsu K, Takabayashi Y. The phytoplasmal virulence factor TENGU causes plant sterility by downregulating of the jasmonic acid and auxin pathways. Sci Rep 2014; 4: 7399.

11 Kazan K, Lyons R. Intervention of phytohormone pathways by pathogen effectors. Plant Cell 2014; 26: 2285-2309. 
12 Liu Z, Zhao J, Liu M. Photosynthetic responses to phytoplasma infection in Chinese jujube. Plant Physiol Biochem 2016; 105: 12-20.

13 Zafari S, Niknam V, Musetti R, Noorbaskhsh SN. Effect of phytoplasma infection on metabolite content and antioxidant enzyme activity in lime (Citrus aurantifolia). Acta Physiol Plantarum 2012; 34: 561-568.

14 Tai CF, Lin CP, Sung YC, Chen JC. Auxin influences symptom expression and phytoplasma colonization in periwinkle infected with periwinkle leaf yellowing phytoplasma. Ann Appl Biol 2013; 163: 420-429.

15 Choi YH, Tapias EC, Kim HK, Lefeber AW, Erkelens C. Metabolic discrimination of Catharanthus roseus leaves infected by phytoplasma using 1H-NMR spectroscopy and multivariate data analysis. Plant Physiol 2004; 135: 2398-2410.

16 Xie N, Yuan Z, Zhang L, Zhao J, Liu MJ. Molecular cloning and expression of a novel eukaryotes elongation factor1A gene (ZjeEF-1a) from Chinese jujube in response to phytoplasma infection. Physiol Mol Plant Pathol 2016; 96: 101-108.

17 Namba S, Kato S, Iwanami S, Oyaizu H, Shiozawa H, Tsuchizaki T. Detection and differentiation of plant-pathogenic mycoplasmalike organisms using polymerase chain reaction. Phytopathology 1993; 83: 786-791.

18 Deng S, Hiruki C. Amplification of $16 \mathrm{~S}$ rRNA genes from culturable and nonculturable mollicutes. J Microbiol Methods 1991; 14: 53-61.

19 Gundersen DE, Lee IM. Ultrasensitive detection of phytoplasmas by nested-PCR assays using two universal primer pairs. Phytopathol Mediterr 1996; 35: 144-151.

20 Liu MJ, Zhao J, Cai QL et al. The complex jujube genome provides insights into fruit tree biology. Nature Commun 2014; 5: 5315.

21 Wisniewski JR, Zougman A, Nagaraj N, Mann M. Universal sample preparation method for proteome analysis. Nat Methods 2009; 6: 359-362.

22 Hervé T, Michel Z, Catherine D, Valerie M. Plant Proteomics: Methods and Protocols. Totowa: Humuana Press. 2007.

23 Wiśniewski JR, Zougman A, Nagaraj N, Mann M. Universal sample preparation method for proteome analysis.[J]. Nat Methods 2009; 6: 359-362.

24 Xiao C, Ye J, Esteves RM, Rong C. Using Spearman's correlation coefficients for exploratory data analysis on big dataset. Concurr Comput Pract Exp 2016; 28: 3866-3878.

25 Boyle El, Weng S, Gollub J, Jin H, Bostein D, Cherry JM. GO: Term Finder-open source software for accessing Gene Ontology information and finding significantly enriched Gene Ontology terms associated with a list of genes. Bioinformatics 2004; 20: 3710-3715.

26 Kanehisa M, Goto S, Furumichi M, Tanabe M, Hirakawa M. KEGG for representation and analysis of molecular networks involving diseases and drugs. Nucleic Acids Res 2010; 38: 355-360.

27 Chen ML, Fu XM, Liu JQ, Ye T, Hou SY, Huang YQ. Highly sensitive and quantitative profiling of acidic phytohormones using derivatization approach coupled with nano-LC-ESI-Q-TOF-MS analysis. J Chromatogr B Anal Technol Biomed Life Sci 2012; 905: 67-74.

28 Hause B, Maier W, Miersch O, Kramell R, Strack D. Induction of jasmonate biosynthesis in arbuscular mycorrhizal barley roots. Plant Physiol 2002; 130: 1213-1220.

29 Dixon RA, Achnine L, Kota P, Liu C, Reddy MS. The phenylpropanoid pathway and plant defence-a genomics perspective. Mol Plant Pathol 2002; 3: 371.

30 Fan G, Xu E, Deng M, Zhao Z, Niu S. Phenylpropanoid metabolism, hormone biosynthesis and signal transduction-related genes play crucial roles in the resistance of Paulownia fortunei to paulownia witches' broom phytoplasma infection. Genes Genomics 2015; 37: 913-929.
31 Dixon RA, Paiva NL. Stress-induced phenylpropanoid metabolism. Plant Cell 1995; 7: 1085-1097.

32 Koskimäki JJ, Hokkanen J, Jaakola L, Suorsa M, Tolonen A, Mattila S. Flavonoid biosynthesis and degradation play a role in early defence responses of bilberry (Vaccinium myrtillus ) against biotic stress. Eur J Plant Pathol 2009; 125: 629-640.

33 Hren M, Nikolić P, Rotter A, Blejec A, Terrier N. 'Bois noir' Phytoplasma induces significant reprogramming of the leaf transcriptome in the field grown grapevine. BMC Genomics 2009; 10: 460-476.

34 Ji X, Gai Y, Zheng C, Mu Z. Comparative proteomic analysis provides new insights into mulberry dwarf responses in mulberry (Morus alba L.). Proteomics 2009; 9: 5328-5339.

35 Curković CM. Auxin-treatment induces recovery of phytoplasma-infected periwinkle. J Appl Microbiol 2008; 105: 1826-1834.

36 Ziegler J, Keinänen M, Baldwin IT. Herbivore-induced allene oxide synthase transcripts and jasmonic acid in Nicotiana attenuata. Phytochemistry 2001; 58: 729-738.

37 Browse J. Jasmonate passes muster: a receptor and targets for the defense hormone. Annu Rev Plant Biol 2009; 60: 183-205.

38 Zhang F, Yao J, Ke J, Zhang L, Lam VQ, Xin XF. Structural basis of JAZ repression of MYC transcription factors in jasmonate signalling. Nature 2015; 525: 269-273.

39 Cole SJ, Yoon AJ, Faull KF, Diener AC. Host perception of jasmonates promotes infection by Fusarium oxysporum formae speciales that produce isoleucine-and leucine-conjugated jasmonates. Mol Plant Pathol 2014; 15: 589-600.

40 Schommer C, Palatnik JF, Aggarwal P, Chételat A, Cubas P, Farmer EE et al. Control of jasmonate biosynthesis and senescence by miR319 targets. PLoS Biol 2008; 6: e230.

41 Jones JD, Dangl JL. The plant immune system. Nature 2006; 444: 323-329.

42 Yi SY, Shirasu K, Moon JS, Lee SG, Kwon SY. The activated SA and JA signaling pathways have an influence on flg22-triggered oxidative burst and callose deposition. PLoS ONE 2014; 9: e88951.

43 Chinchilla D, Bauer Z, Regenass M, Boller T, Felix G. The Arabidopsis receptor kinase FLS2 binds flg22 and determines the specificity of flagellin perception. Plant Cell 2006; 18: 465-476.

44 Robatzek S, Bittel P, Chinchilla D, Kochner P, Felix G, Shiu SH. Molecular identification and characterization of the tomato flagellin receptor LeFLS2, an orthologue of Arabidopsis FLS2 exhibiting characteristically different perception specificities. Plant Mol Biol 2007; 64: 539-547.

45 Smith JM, Salamango DJ, Leslie ME, Collins CA, Heese A. Sensitivity to Flg22 is modulated by ligand-induced degradation and de novo synthesis of the endogenous flagellin-receptor FLAGELLIN-SENSING2. Plant Physiol 2014; 164: 440.

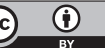

This work is licensed under a Creative Commons Attribution 4.0 International License. The images or other third party material in this article are included in the article's Creative Commons license, unless indicated otherwise in the credit line; if the material is not included under the Creative Commons license, users will need to obtain permission from the license holder to reproduce the material. To view a copy of this license, visit http://creativecommons.org/licenses/ by/4.0/

(c) The Author(s) 2017

Supplementary Information for this article can be found on the Horticulture Research website (http://www.nature.com/hortres) 